\title{
El biopoder patriarcapitalista y la destrucción de la masculinidad: la resistencia en clave femenina y feminista.
}

\author{
Camila V. Bordón Gabriele \\ Estudiante del Profesorado y la Licenciatura en Filosofía \\ Universidad Nacional del Nordeste \\ cam.bordon@gmail.com
}

\section{Resumen}

El feminismo permite nuevas formas de interpretar la propuesta foucaultiana sobre la biopolítica. El biopoder se emplaza en una estructura patriarcapitalista, heredera del Estado moderno, donde sus mecanismos de control de la población se vuelven claves en el cuerpo percibido femenino o cuerpa, término apropiado por el feminismo contemporáneo. El entramado de luchas no es solo en política, en términos de esfera pública, sino que la vista se vuelve sobre el espacio doméstico, lugar que históricamente se asocia y se restringe a la feminidad. En él hay cuatro mecanismos representativos: el sexo falocéntrico, el aborto, el parto y el feminicidio.

Estos mecanismos disponen fuerzas productivas en el trabajo, en una lógica binaria, jerárquica y sexual. Operan como estrategias dos figuras, tomadas de la antropóloga Rita Segato, el varón moralizador y la mujer sospechosa.

El análisis del juego poder-resistencia permite el encuentro de puntos de fuga. EI espacio de lucha es principalmente el lugar doméstico, lo privado o lo íntimo, lo otro binario en relación al Estado y al interés público. La resistencia es al saber normalizador de las prácticas de lo cotidiano, que significa normalizar sobre los cuerpos y la vida principalmente de mujeres e identidades que se perciban femeninas.

Palabras claves: biopolítica, patriarcapitalismo, control, feminismo, vida.

\begin{abstract}
Feminism shows new ways of interpreting the foucaultian proposal about biopolitics, placed in a patriarch-capitalist structure, thought as the heir of the modern
\end{abstract}


State, which population control mechanisms become the key for the perceived female body or cuerpa, a term appropriated by contemporary feminism among the spanish speaking culture. The string of struggles isn't strictly in the field of politics in terms of public context, but it is also evident in the domestic space, place historically confined and associated to femeninity. Biopolitics encloses four representative mechanisms: phallocentric sex, abortion, childbirth and femicide

These mechanisms have productive forces in the work. In a binar logic, hierarchical and sexual. They strategically take two figures to operate: the moral man and the suspicious woman. The analisis of the "power-resistence" game leads to the encounter of leak points. The court of the struggle is mainly the domestic place, the private and the intimacy. The other part is in relation to State and public interest. The resistence is the normalizing knowledge of every day life practice, which means to normalize among the bodies and lifes of women and identities percived as women.

Keywords: biopolitics, patriarch-capitalism, control, feminism, life.

\section{Introducción}

El presente trabajo se pensó en función de la cátedra Seminario II: análisis de una problemática filosófica, de las carreras de Filosofía de la facultad de Humanidades de la UNNE. Siendo la problemática propuesta la cuestión de la vida en la filosofía biopolítica, se pretende abordar la vida, el sexo y los cuerpos, controlados en la población por mecanismos que aparecen como puntos de fuga en la definición jurídica y a veces contradictoriamente en la ética. El espacio de lucha es principalmente el lugar doméstico, lo privado o lo íntimo, lo otro binario en relación al Estado y al interés público, como saber normalizador de las prácticas de lo cotidiano, que significa normalizar sobre los cuerpos y la vida principalmente de mujeres e identidades que se perciban femeninas.

Estos mecanismos biopolíticos se emplazan en una estructura patriarcapitalista: por un lado, sustenta las relaciones para el desarrollo del capitalismo en tanto fuerzas productivas a disposición del trabajo; y por otro, operan como estrategias dos figuras, 
tomadas de la antropóloga Rita Segato, el varón moralizador y la mujer sospechosa. En estas figuras se entraman cuatro mecanismos representativos del patriarcapitalismo biopolítico: el aborto, el parto, el sexo -falocéntrico- y el femicidio.

Las grandes cifras de muertes por abortos clandestinos, las expresiones de miles de personas en los reclamos en materia de violencia obstétrica, en la socialización del saber femenino y un abordaje integral y completo, el número en aumento de los feminicidios en nuestro país, Argentina, y en el mundo, impulsan la reflexión en torno a la problemática biopolítica, porque se inscriben en el cuerpo y operan desde ahí el control de la población: sobre el propio placer y el sexo, a partir del binarismo sexual con base en el falocentrismo, en la regulación de los nacimientos y también en las formas de nacer, y en el castigo a la falta moral que puede implicar hasta la muerte.

Se renueva el planteo del filósofo Michel Foucault sobre los entrecruzamientos históricos que conforman valores, instintos y graduaciones en relación a las políticas del cuerpo, en torno a una moral normalizadora patriarcapitalista evidenciada en figuras teorizadas por la autora argentina Rita Segato.

La hipótesis que se desarrolla es que, gracias a los aportes del feminismo es posible pensar una biopolítica que emplace el biopoder en una estructura patriarcapitalista. El control del cuerpo, el sexo y la vida se ejercen a través de dispositivos que toman las figuras del varón moralizador y la mujer sospechosa como mandatos morales. Pero no se reduce a un plano cultural, social o personal, sino también se efectiviza en medidas estatales, políticas o jurídicas, amparadas por la lógica binaria del género.

En primera instancia, se definirá qué conceptos del filósofo francés se toman desde el feminismo. Se analizará el concepto de biopolítica y las relaciones posibles con las propuestas feministas en relación a prácticas sobre el cuerpo.

En segundo lugar, se definirá la noción de patriarcapitalismo y las razones por las cuales es posible relacionarla con la biopolítica, a su vez con la ética, y las implicancias en las construcciones de la subjetividad en el patriarcapitalismo, en el juego biopoder-resistencia. 
Para conseguir estos objetivos, se indicará el binarismo de género como estrategia principal en el patriarcapitalismo y desde el cual se posibilita la emergencia del biopoder y sus aplicaciones. Se conceptualizará al varón moralizador y a la mujer sospechosa de Rita Segato, exponiendo sus características y lo que disponen en el cuerpo no solo individual sino social, no como dualidad macho-hembra, sino como binarismo de género en la creación de dos espacios de valor moral. Se ejemplificarán ámbitos donde se expresan los conceptos del varón moralizador y la mujer sospechosa: el aborto, el parto, el sexo y el feminicidio, no como categorías exhaustivas de análisis sino como lugares representativos de expresión del biopoder, a partir de lo expuesto.

La técnica de investigación es principalmente la de fichaje bibliográfico, a través del análisis de las obras de los autores, de entrevistas, y artículos de autores que conceptualizan al respecto.

\section{El biopoder en la escena feminista: el cuerpo y las cuerpas.}

La reflexión en torno al cuerpo y su disciplinamiento obliga a releer al filósofo francés Michel Foucault en sus análisis sobre biopolítica y sexualidad. Al mismo tiempo, la realidad sobre el poder de hacer vivir o dejar morir que recae históricamente sobre las mujeres con mayor fuerza y menos visibilidad política, exige tomar esos análisis a la luz de las teóricas feministas que los problematizan y con quienes "se denuncia el carácter masculinista de su retórica, el androcentrismo de su perspectiva y el pesimismo de su visión" (Boyer, 2012, p.131). Esto no implica descartar los aportes del filósofo, sino antes bien devenirlos feministas.

Cabe destacar que ya existía, previo a la publicación de la Historia de la Sexualidad, teorizaciones feministas de pensadoras reconocidas como Simone de Beauvoir y Luce Irigaray, también en Francia como el filósofo. La omisión de la crítica feminista en la obra del autor produce divergencias en el feminismo respecto a la propuesta del filósofo: desde el rechazo hasta la aceptación total o parcial de su proyecto. 
El punto de acercamiento entre feminismo y biopolítica, en este caso desde Michel Foucault, refiere principalmente a conceptos vinculados con el cuerpo, el poder, la subjetividad y la sexualidad. El territorio del cuerpo es el acceso a la problematización de la opresión hacia las identidades que se entienden femeninas, como de la inscripción violenta de las identidades masculinas: es la binarización que se enuncia desde la sexualidad y que se supone orgánica y fisiológica. Pensarlo en términos de biopolítica permite no reducirlo a una cuestión de cultura, sino en tanto vida entendida como poder. Al tratarse de un biopoder, entonces se vuelve admisible analizar sus condiciones de posibilidad, sus supuestos, las tecnologías que operan y los dispositivos que tienen alcances políticos y éticos, no ya sobre un cuerpo individual o un discurso, sino sobre un conjunto de seres vivos que tienen rasgos biológicos en común: la población como objetivo de la biopolítica.

En este sentido, los análisis del filósofo francés van a hacer posible pensar una biopolítica desde la mirada feminista. En principio conviene aclarar de qué se trata la biopolítica y por qué se referiría al feminismo o a las lecturas de feministas.

Foucault diferencia dos mecanismos de poder: anatomopolítica y biopolítica. Cada una tiene sus características pero es importante marcar que, al tratarse de dos planos diferentes de acción, no son excluyentes e incluso se articulan entre sí, unos sobre otros.

La anatomopolítica resume mecanismos de disciplinamiento del cuerpo individual. Produce efectos individualizadores. Adiestra el cuerpo, que se lo considera como organismo dotado de capacidades (Foucault, 2001, p. 226). Sus formas son locales, en un marco limitado, en instituciones como la escuela, la fábrica, los hospitales, la cárcel, etc. Su objeto es el cuerpo individual, en tanto disciplina la multiplicidad. Las acciones que puede realizar son las de “...vigilar, adiestrar, utilizar y, eventualmente, castigar" (Foucault, 2001, p. 220).

La biopolítica, en cambio, consiste en mecanismos de regularización de seres dotados de vida (específicamente humana) como masa o especie, es decir, su objeto es la población. La población es entendida como problema político y científico. Trata de fenómenos en serie que tienen una duración en el tiempo. Actúa globalmente 
pretendiendo equilibrio y regularidad. Las acciones son las de controlar o modificar la probabilidad o efectos de masa en una población referidos a la vida (Foucault, 2001). Sus formas son globales, lo que significa que implica órganos más complejos para coordinar sus acciones: organismos dependientes del Estado, en relación a una tecnología aseguradora. Su instrumento es principalmente la estadística en relación a la natalidad, la morbilidad, la sexualidad, la enfermedad, la higiene pública, la vejez, la incapacidad, pero tiene una implicancia modificadora, no solo recopiladora de información.

En la sexualidad confluyen lo biopolítico y lo anatomopolítico porque se da a la vez el disciplinamiento de los cuerpos individuales y la regulación de masa en la población. "El sexo es, a un tiempo, acceso a la vida del cuerpo y a la vida de la especie. Es utilizado como matriz de las disciplinas y principio de las regulaciones" (Foucault, 2007, p.176) Se ejercen distintas estrategias sobre el dispositivo de sexualidad cuya función es, de forma general, organizar el apoderamiento de los cuerpos en torno a un elemento ideal y especulativo como el sexo, en tanto agrupa artificialmente como significante único y significado universal, resume el saber de la sexualidad humana y de las ciencias de la reproducción y permite establecer líneas de contacto en relación al poder.

Por los fines de este trabajo monográfico, no es pertinente detenerse en las estrategias, sino antes bien recuperar el concepto de sexo y las formas en las que se estructura y disciplina la vida. En el sentido de su practicidad, la noción del sexo es acceso a la propia inteligibilidad, a la totalidad del cuerpo y a la identidad en relación a la fuerza de pulsión y la singularidad de una historia (Foucault, 2007). Es el mismo dispositivo el que establece como punto ficticio al sexo, que funciona como acceso a técnicas de poder para la invasión de la vida. El dispositivo de sexualidad está sustentado en estrategias y astucias de sexualidad que conforman un discurso articulado con el cuerpo, funciones biológicas, placeres, que operan como mecanismos de poder para controlar y regular lo cotidiano de la sexualidad.

El sexo, entonces, es una idea formada en el interior del dispositivo, que se da históricamente y a través de diferentes estrategias de poder. Tiene sus leyes propias 
que articulan el discurso para ordenar el funcionamiento del dispositivo de sexualidad. La noción de sexo es el apoyo especulativo de la figuración histórica de la sexualidad. Se advierte como un núcleo fuerte de "fascinación" y aceptación, como instancia sobre el poder, los cuerpos y los saberes.

De esta manera, sexualidad y poder están íntimamente vinculados en Foucault, y así también lo entenderán las críticas feministas. El encuentro de la perspectiva foucaultiana y la feminista será entonces en la aceptación de que existe un entramado discursivo de poder y saber a partir del cual se produce el concepto de sexo dentro del dispositivo de sexualidad. La diferencia radica en que las feministas lo aplicarán a la construcción de la sexualidad femenina: "...el género produce normativamente el sexo y luego lo oculta como realidad pre-discursiva" (Posada, 2015, p.33).

El cuerpo sexuado binario no es lo real sobre lo que el poder extiende su dominio y control: es la misma producción del biopoder. Cuando se habla del cuerpo, se piensa en un cuerpo particular, el cuerpo normal, del varón que es adulto, occidental, blanco, burgués, heterosexual, monógamo y en plena función de sus capacidades posibles cognitivas y motrices. Pero no es el cuerpo único el que se disciplina y que las tecnologías de la sexualidad tienen como objetivo. En relación a esto es que muchas feministas afirmarán que en Foucault el dispositivo de sexualidad está construido sobre una pretendida asexualidad (Posada, 2015) por omitir la mitad del mismo, la parte femenina.

El nombrar un cuerpo diferente es mostrar eso otro que existe pero que no se nombra, porque no nombrarlo es también ocultarlo como normalizador. Este significado se subsume en un concepto que las feministas de la actualidad comienzan a utilizar: las cuerpas. No uno solo, no una sola: plural y en femenino. Esta aplicación disruptiva del lenguaje muestra un territorio inexplorado de la realidad biopolítica: sobre el territorio que es el cuerpo de la mujer, la cuerpa, se inscriben expresiones del biopoder, el núcleo de las tecnologías productoras de normas, que no son contemporáneas sino modernas y que operan como estrategia económico-política liberal. De aquí se desprende una importante premisa de la crítica feminista: al dispositivo de sexualidad hay que analizarlo como indisociable del patriarcapitalismo. 


\section{Por qué patriarcapitalismo y no solo el sujeto moderno y el trabajador}

Definir la noción de patriarcapitalismo requiere volver sobre la modernidad, donde se encuentran las condiciones en las que el poder ingresa al dominio de la vida. La condición principal es la alianza entre prácticas liberales y la moral de lo Uno y del sujeto universal bajo la tutela del Estado. Esta alianza es la gran estrategia del patriarcapitalismo.

En palabras de Foucault, “...el capitalismo que se desarrolló a finales del siglo XVIII y comienzos del XIX, socializó un primer objeto, que fue el cuerpo, en función de la fuerza productiva, de la fuerza de trabajo. El control de la sociedad sobre los individuos no se operó simplemente a través de la conciencia o de la ideología, sino que se ejerció en el cuerpo, y con el cuerpo (Foucault, 1999). Es con el capitalismo donde se produce al cuerpo y a la vida en función del trabajo, en primer término. No puede dejarse de lado su vinculación con la política, que también el mismo filósofo afirma "el hombre moderno es un animal en cuya política está puesta en entredicho su vida de ser viviente" (Foucault, 2007, p.173).

Las producciones del biopoder emergen a la par del Estado moderno y no resulta inadmisible pensar al mismo Estado como creación misma de regulación de los espacios donde el biopoder se ejerce positivamente. $\mathrm{Y}$ en este sentido, para hacer explícita la configuración del patriarcado y de su desarrollo histórico se requerirá necesariamente entender los conceptos de Estado y de esfera pública, en un mismo entrecruzamiento histórico de emergencia. De la misma manera que no puede negarse la implicancia de las formas de gobierno liberales que atraviesan la constitución moderna del Estado. La antropóloga Rita Segato enlaza estos conceptos en su obra La guerra contra las mujeres, afirmando que

el Estado, con su estructura patriarcal [...] está concebido y diseñado para ser apropiado por las élites o para entronizar a los nuevos segmentos de la sociedad y elitizarlos cuando se tornan parte del gobierno. Y, sobre todo, para mantener la matriz binaria que ha establecido que existen temas del sujeto universal, siempre con la $\mathrm{H}$ mayúscula que vincula lo Humano al Hombre, y 
temas de la domesticidad parcializada, reducida, minorizada. (Segato, 2017, p.105)

Hasta este punto, se encuentra una vinculación política entre el Estado, la fuerza de trabajo en el capitalismo y la forma de gobierno, una racionalidad liberal. Para comprender mejor de qué se trata la proposición de Segato sobre el sujeto universal, resulta esclarecedor volver sobre la crítica al sujeto moderno que esgrimía Nietzsche, y que retoma el mismo Foucault.

Nietzsche critica al sujeto moderno y puede resumirse a la crítica de la proposición cartesiana y kantiana del "Yo pienso", en la que ve una confusión. Está confusión a la que refiere tiene su fundamento en la historia de los sentimientos morales en la cual se hace a alguien responsable, lo que implica un error en la designación de las cosas y otro error al tomar las consecuencias por causas. Sucesivamente se hace responsable al hombre de su influencia, actos, motivos y finalmente de su ser mismo.

El ser causa de sí mismo, o causa sui, lo llama Nietzsche la autocontradicción excogitada, como un sinsentido en el que ha caído el hombre moderno por su propia vanidad y confusión, donde el espíritu se percibe como causa, como realidad a la vez que como medida de la realidad e incluso llamándolo Dios.

Nietzsche (2005) va a afirmar que “...causa y efecto son conceptos puros, es decir, ficciones convencionales con fines de designación, de entendimiento, pero no de explicación" (p.46) lo cual extrae de raíz el planteamiento moderno: lo que describe como hechos causales y consecuenciales no son más que parcialidades que fueron aisladas por el mismo sujeto y puestas en sucesión de forma arbitraria. Esto no podría condecirse con la realidad, que es de flujo continuo, y designarla creyendo que se alude a su esencia es un sinsentido y una acción risible.

El sujeto moderno designa y enuncia, a la vez que universaliza su discurso, que es lo propio de la racionalización de la realidad y de la vida. Porque no solo se trata de causas y efectos del exterior, del mundo de las cosas que rodean al cuerpo, sino también del interior: los instintos, las pasiones, etc., que sufren la misma suerte de ser designados y entendidos racional y lógicamente por signos que no son análogos a 
ninguna esencia, aunque tengan la pretensión. El ámbito en el que se encuentra esta crítica es desde la moral. El filósofo alemán se referirá a los "despreciadores del cuerpo", o también sapientísimos u hombres del conocimiento, puede considerarse que poseen una voluntad de verdad, que Nietzsche (2003) llama "Voluntad de volver pensable todo lo que existe..." (p. 174).

Se desprende de esta crítica la relación saber-poder, que es central en el dispositivo de sexualidad. Entonces, se desarrolla por un lado una forma de gobierno liberal y en la misma frecuencia de sentido una racionalidad universal y universalizante de lo Uno y la verdad. Desde esta perspectiva, no hay una diferencia real de la propuesta foucaultiana, puesto que ya lo enuncia el filósofo dentro del dispositivo de sexualidad, con las estrategias del poder, el desarrollo de la medicina y la patologización del sexo.

Pero en Foucault el dispositivo de la sexualidad parte del saber del dimorfismo biológico, y no parece cuestionarse a qué intereses ha servido y sirve históricamente el mismo. Porque la "La histerización del cuerpo de la mujer" no contempla en Foucault cómo esta patologización supuso, a la vez, la conversión del sexo masculino en norma. Y cómo, de este modo, las mujeres son además conceptualizadas como lo otro de los hombres, negándoseles el principio de individuación que sólo correspondería a lo masculino. (Posadas, 2015, p.40)

La conexión entre una racionalidad de Estado y la racionalidad moral confluye en que, para enunciar un discurso válido que tenga carácter universal y que sea de interés general, debe darse en una esfera pública. La racionalidad no deja de ser una invención que se presume devenida de una realidad prediscursiva, pero es una ficción, también parte de la confusión de una lógica del Yo pienso.

El posicionamiento del Yo pienso y de lo Uno establece una relación jerárquica y binaria. Lo que lo hace propiamente patriarcapitalista es que elabora la posición de un sujeto paradigmático Humano, que va a ser masculina que va a proponer lo masculino como norma, y rechaza o margina "lo otro", que en este caso es la posición femenina. “...La esfera pública es el único espacio donde lo que se habla tiene impacto político en la totalidad de las personas. Quien quiera hablar ahí, va a tener que 
adaptarse, aprender a comportarse, ciertas formas de corporalidad, ciertas vestimentas" (Segato, 2017, p.168).

Se puede afirmar que el Estado es el armazón de un dispositivo patriarcal que engloba las redes de poderes que disciplinan los cuerpos y que crea las diferencias de sexo, que son diferencias también de género. Pero no solo son diferencias, son una serie de prácticas, de roles asignados que se dan como naturales y única opción, y que favorecen no ingenuamente la producción y las relaciones de mercado. El Estado que se creó en la modernidad, es correlato del sujeto moderno que universaliza y que propone el interés general, que es también el trabajador fabril que sostiene la producción y al mismo tiempo funciona con el burgués dueño de los medios de producción, porque se trata del varón blanco heterosexual como norma, y la diferencia es otro lugar, dicotómico y en apariencia contrapuesto: la mujer, lo doméstico, el cuidado, lo subjetivo.

\section{Lo biopolítico es personal.}

La consigna feminista que más repercutió en las discusiones sobre identidades femeninas y violencia, que fue la que reunía a las feministas en las luchas de los años 70 en Argentina y en muchos países de Occidente, es "lo personal es político". Lo que se pretende con esta premisa es poner en el debate del interés público, darle relevancia política, a aquello que se reducía al espacio "personal" o "íntimo" de lo doméstico.

Lo que el movimiento feminista estaba sugiriendo es que existen prácticas que se agencian en lo privado y que reclaman un devenir político para su análisis e intervención. Semánticamente a estas prácticas se las reconoce universales y de interés, pero su eje de análisis y consideración material las circunscribe a la privacidad. Estas prácticas son crímenes que se perpetúan sobre las cuerpas, el cuerpo que se lee femenino o se feminiza. Su retórica de privacidad y su peso simbólico de anulación y de constitución de las cuerpas como territorios no radica en su carácter político, sino en el biopoder que las produce en ese sentido. Se construyen estereotipos de género que asocian lo femenino con lo íntimo, y de esta forma "...todos los tipos de crímenes 
contra las mujeres se encuentran contaminados, en el imaginario colectivo, por la atmósfera del espacio de intimidad, es decir, la domesticidad nuclearizada privatizada propia de los tiempos modernos" (Segato, 2017, p.87).

El patriarcapitalismo como dispositivo opera en dos sentidos, dicotómicos como norma, sobre esta cuestión. Por un lado, implica que el interés público es masculino, es espacio del varón. Por otro lado, que la mujer se debe al espacio doméstico, que tiene menor valor. Es decir, crea roles de género jerarquizados basado en una diferencia del supuesto carácter binario del sexo, en apariencia de realidad prediscursiva.

La manera de determinar esta jerarquización es, retomando un poco lo que se desarrolló en el segundo capítulo de este trabajo, que la esfera pública produce verdades universalizables, de interés general e intereses de mercado. Es el lugar propiamente político. El espacio doméstico o privado es subjetivo, es el trabajo de cuidado y de sostén del hogar en lo inmediato y lo cotidiano, totalmente desprovisto de política por su incapacidad de producir enunciados universalizables. El patriarcapitalismo, a través de esta binarización, "expurga de ese modo todo lo que no le concede el reconocimiento debido a su forma de estructurar y disciplinar la vida, a su forma de habilitar y naturalizar un camino de asimetrías y dominaciones progresivas" (Segato, 2017, p.96).

Al mismo tiempo, la sexualidad está estrictamente relacionada a lo privado, a lo que debe reservarse, lo que debe ocultarse o moderarse. En este sentido, lo biopolítico es en lo personal, en relación a la consigna de las feministas de los 70 , porque no se trata de convertir en política el oikos, que lo desvirtuaría, sino reconocer el biopoder en ese espacio privado y localizar las tecnologías de comportamiento patriarcales a través de las que se ejerce en este plano, que es estrictamente biopolítico y ético.

No es meramente un espacio que se impone sobre otro, sino dos matrices del mismo patriarcapitalismo, que vuelve binario sus espacios vitales o biolugares: el de lo masculino y el de lo femenino. No se trata solo de un cuerpo y cuerpas determinados patriarcalmente; se trata del control del comportamiento desde la disposición 
identitaria mientras se lea masculina o femenina, donde se ejercen los biopoderes respondiendo a principios de la economía liberal y de la política masculina.

Es importante destacar que la estructura está construida de prácticas puntuales, violentas, sobre las cuerpas, que regulan sus vidas desde la sexualidad y que operan normalizando, con valores morales que se ejercen desde la posición masculina y desde sí misma. En palabras de Rita Segato, el patriarcado

...establece la relación jerárquica que llamamos "género" como estructura binaria y desigual por la cual la posición masculina secuestra para sí la plataforma de enunciaciones de verdades de interés universal llamada 'esfera pública' y se coloca en la posición de sujeto paradigmático de lo Humano pleno y englobante, en un gesto que expulsa a la posición femenina a la calidad de margen, resto, particularidad, cuestión de intimidad. La agresión bélica sexualizada a mujeres y a niños, es decir, a aquellos que no ocupan la posición de sujeto antagonista en la guerra, representa una agresión simultáneamente física y moral a cuerpos cuya existencia debe darse bajo custodia, es decir, que por definición son cuerpos tutelados. (Segato, 2017, p.83)

Cuando se expresa que la sexualidad se delimita a lo privado, también se está delimitando una estrategia del biopoder para mantenerse desde lo privado ejerciéndose políticamente. La agresión bélica hacia las identidades femeninas tiene una carga simbólica y moral que pretende inscribirse en ese territorio, que en esas cuerpas las interpela como culpa de sí mismas y en una paradójica condena al lugar de víctima.

La agresión bélica no es estrictamente sexual, sino que se vehiculiza en lo sexual en la relación saber-poder y en el control de la vida. La categorización de agresión sexual lo restringe rigurosamente a lo privado, apolítico. Es radicalmente distinto considerarlo una agresión de poder, porque entonces en el discurso debería operar con carácter de interés general, político y en directa confrontación a la posición masculina. Esta imposibilidad de profundizar en ese sentido es un límite de la moralidad. 


\section{De él la moral, de ella la culpa.}

En la esfera pública se enuncian verdades universalizables y de interés general. En el espacio privado, habita lo subjetivo y lo apolítico, en la lógica patriarcapitalista. Lo que se esconde es el funcionamiento de una moral que dispone el disciplinamiento y el control del cuerpo y de las cuerpas, que es también una moral heredera de planteos modernos y cristianos.

Esta moral, que se impone con violencia, es “...el conjunto de mecanismos legitimados por la costumbre para garantizar el mantenimiento de los estatus relativos entre los términos de género" (Segato, 2010, p.105).

Se distinguen dos tecnologías de biopoder reconocibles en dos figuras: el varón moralizador y la mujer sospechosa. No refiere estrictamente a un cuerpo sexuado macho o hembra, aunque aparenta, sino a dos lugares a los que pertenece la población mediante los que se controla y disciplina.

El varón es enunciador de una moral de verdades universales, y la mujer un agente del silencio victimizado, inmóvil en el lugar femenino. La relación del biopoder es a través de la sexualidad, o lo que en la práctica es análogo a la sexualidad. Simbólicamente tiene una carga diferente. Es decir, una penetración puede ser sexo en determinadas condiciones o violación en otras. Lo moralizador no está en el sexo en sí, sino en el poder con el que esa sexualidad se ejerce, y en el discurso desde el cual el sexo se constituye.

El lugar del varón es el de la racionalidad, de la verdad, de la política, de la objetividad, de la colonización y la conquista. Mantiene estas características bajo la condición de un mandato moral de masculinidad.

La sexualidad, principalmente la sexualidad femenina, es el punto de acceso a lo privado y la tecnología estructurante del control de la población. Hay determinados espacios, privados pero convenientemente hechos públicos, en favor de la posición masculina, según el caso, en los que se expresa con claridad la biopolítica desde esta perspectiva. La sexualidad es controlada, el saber jerarquiza, el derecho revictimiza, se manipula el cuerpo disciplinándolo y se decide sobre la vida o la muerte. 
Son cuatro espacios, como pudieran ser cinco o más, pero a fin de explicar sobre esta temática es atinente tomar solo cuatro. Respecto al control, el sexo es uno de esos espacios. Obligadamente heterosexual, monógamo y falocéntrico. El aborto es otro, donde en materia de derecho en Argentina se establece vida humana desde la concepción, y se admiten legalmente interrupciones de embarazos en algunos casos, pero en caso de no cumplirse, no hay sanción ni repercusión. No solo controla la natalidad sino que define qué mujeres podrán parir, qué mujeres podrán abortar y cuáles morirán, en un entramado de negociado mercantilista. También el parto, donde se decide cómo nacer, cómo parir: el saber médico se posiciona por encima de la capacidad fisiológica de la gestante y parturienta, anulando toda decisión posible. El cuarto espacio es el femicidio, donde el hacer morir es la máxima expresión del biopoder patriarcal.

Todos estos espacios son relegados al ámbito privado y de alguna manera politizados en favor del disciplinamiento y control de la población: son prácticas sexuales moralizadoras por parte del varón y culpabilizadoras de la mujer, que no guardan tanta relación con el placer y el erotismo como sí con el poder. Un quinto espacio muy representativo también es el de la violación, pero se omitirá en este trabajo por el abordaje exhaustivo que realiza la antropóloga Rita Segato al respecto.

En relación al sexo, se lo considera en sentido estricto a la penetración. El sexo es una elaboración falocéntrica heteronormada. En el imaginario se representa a una mujer que es pasiva y susceptible de recibir lo que el varón puede dar: el binarismo se corresponde en el sexo. El lugar del placer aparece en simultáneo al poder y se confunden. En el sexo, hay placer en el orgasmo del varón y hay una simulación de placer en la mujer, porque en el varón hay una exigencia moralizadora y en ella, la culpa.

En el caso del aborto, es una estrategia contemporánea perseguir a las que abortan. Tiene varias aristas a tener en cuenta. Es una manera de ocultar los negocios del aborto clandestino declarando su ilegalidad. Es también un control de la natalidad atravesado del saber médico: hasta la modernidad, las matronas eran las que ayudaban a abortar, pero no había una instrumentalización especializada. Al mismo 
tiempo, se asume que el cuerpo gestante es territorio en disputa, y desde esta noción territorializada, toda construcción de la subjetividad va a encontrarse en relación a la culpa, porque debe confrontarse con el varón moralizador que determina la territorialidad de esa cuerpa sobre la que ejercerá poder. Tampoco es menor considerar que, en el Derecho Argentino, se considera vida humana desde la concepción: es decir, la unión con lo que el varón provee es lo que determina una vida humana, y por lo tanto valiosa, y no las labores del gestar, parir o maternar. Determinar el inicio de la vida humana desde esta perspectiva es de interés público y universalizable, por eso hasta el derecho lo contempla. Ahora bien, gestar, parir y maternar pertenecen al ámbito privado, femenino, marginalizado. Obligar a alguien a hacer sobre su cuerpo lo que no admite es considerado tortura, y es de interés político, excepto si se trata de aborto, que implica una cuerpa, que es, entonces, donde vuelve a ser sexualidad y espacio íntimo, apolítico y subjetivo y por lo tanto, no puede pronunciarse contundentemente al respecto.

El parto es la instrumentalización por excelencia del saber-poder. Es el acto que deviene médico por la presión para su patologización. Se moraliza a través de la minorización de las potencialidades fisiológicas de la parturienta. Se interviene con mutilaciones genitales, con privaciones de movimiento, con aceleración y acentuación artificiales de las contracciones uterinas. La parturienta asume la culpa instalada de no saber parir.

El femicidio es el crimen que más evidencia la dificultad de considerarlo un tema de interés público. El homicidio lo es, pero el femicidio todavía tiene la carga de lo doméstico, de lo pasional y subjetivo. Rita Segato va a considerar al femicidio a modo de expresión del poder soberano: “En un régimen de soberanía, algunos están destinados a la muerte para que en su cuerpo el poder soberano grabe su marca; en este sentido la muerte de estos elegidos para representar el drama de la dominación es una muerte expresiva, no utilitaria" (Segato, 2017, p.39). El femicidio representaría la forma más violenta en la que el varón moraliza a una mujer que ha desobedecido. Él por defensa al mandato de masculinidad, la expresión de poder, y ella por resistencia a ese lugar. 


\section{La resistencia y la ruptura en clave femenina (y feminista)}

En los análisis sobre el poder de Michel Foucault, la resistencia aparece como indisociable de este. No funciona uno, sin la otra, y presentan las mismas características. No es un juego diálectico, sino antes bien una positividad creadora de estrategias. Esta cualidad hace al poder también estrechamente vinculado con la libertad y la constitución de la subjetividad, que es lo que Foucault declara que es el objeto de sus problematizaciones.

Partiendo de este punto, hay dos planos a atender, en simultáneo, en relación a la resistencia al poder patriarcapitalista: la sexualidad y la ética.

Foucault va a diferenciar dos éticas: una, grecorromana, y otra a la que va a llamar ética de la carne que es herencia del cristianismo. La primera guarda íntima relación con el deseo y el placer en una vinculación que autoconstituye al sujeto en un souci de soi (cuidado de sí). La ética de la carne divide esa relación entre deseo y placer los asocia a elementos prescriptivos, estableciendo códigos de conducta moral.

La ética grecorromana descrita por Foucault, sobre todo en el segundo volumen de la Historia de la sexualidad, El uso de los placeres, tiene por sustancia ética los aphrodisia, y su modo de sujeción es una elección personal estético política (no se trata tanto de respetar un código como de "hacer de la propia vida una obra de arte"). (Revel, 2009, p.68)

Los aphrodisia son actos, gestos o contacto que permiten placer. Su noción es práctica y no necesariamente es sexual en relación a otro, sino que es una experiencia estética, en consonancia con el deseo y el cuidado.

Esta noción ética vinculada con la sexualidad, no pretende liberar la sexualidad del poder, sino antes bien constituir al sujeto a partir de modalidades de objetivación registrando la "verdad del individuo" (Revel, 2009) o una autoconstitución de sí.

La relevancia de esta propuesta ético-sexual es que ofrece un lugar de resistencia que se asemeja mucho a la posición femenina. Por otro lado, de ofrecer solo resistencia, no cambiaría más que determinados lugares en el juego de poderresistencia. Es decir, debe encontrarse también una ruptura, una fuga a esa resistencia 
que desde alguna exterioridad permita subvertir la moralidad binaria y las estrategias de poder patriarcal: la ruptura es la destrucción de la masculinidad.

Un texto escrito por Félix Guattari (2016) Para acabar con la masacre de los cuerpos, plantea la destrucción de la sexualidad, pero es en este sentido de destrucción del binarismo, es también la destrucción de la masculinidad. En este texto plantea la observación subjetiva de las relaciones que atraviesan y constituyen al sujeto, y cuya "liberación" no puede darse simplemente desde el placer, modificando las formas. El placer es un lugar de resistencia, pero es necesaria la ruptura: “...del deber conyugal a la promiscuidad voluntarista de las orgías burguesas, no existe ninguna ruptura. Es la misma censura lo que está obrando. Es la misma masacre del cuerpo deseante lo que se perpetúa. Simple cambio de estrategia" (Guattari, 2016). Además, agrega que

“...conocemos en particular que la liberación del cuerpo, de las relaciones sensuales, sexuales, afectivas y extáticas, está indisolublemente ligada a la liberación de las mujeres y a la desaparición de todas las formas de categorías sexuales. La revolución de deseo pasa por la destrucción del poder masculino y de todos los modelos de comportamiento y emparejamiento que aquél imponga, así como pasa por la destrucción de todas las formas de la opresión y de normalidad" (Guattari, 2016)

La destrucción de la masculinidad es la apertura a la posibilidad de un devenir estético, que parte del placer como lugar de resistencia, pero su propuesta es superadora. Habitar el espacio femenino es la subjetividad, lo particular, lo que está desprovisto de política pero completamente constituido desde el biopoder. Segato planteaba la necesidad de

“...hacer una política del día a día, por fuera del Estado: retejer el tejido comunitario, derrumbar los muros que encapsulan los espacios domésticos y restaurar la politicidad de lo doméstico propia de la vida comunal. [...] Es la política de las mujeres que ahora tienen su vez". (Segato, 2017, p.106)

La destrucción de la masculinidad es también la destrucción del Estado patriarcal. 
No se trata de abandonar el camino estatal de una vez, sino partir desde la resistencia, entendiéndola en el lugar de lo femenino. Es resistir y a la vez constituir un espacio de ruptura que sea por fuera, exterior, que se fugue de la misma resistencia.

Esta propuesta seguiría en consonancia con las luchas feministas de la actualidad. La consigna que engloba la mayoría de ellas es la de "muerte al macho", que es la exigencia de la extinción o destrucción de la masculinidad violenta, que en este trabajo es toda masculinidad, porque constituye a un sujeto de poder cuya moralidad debe reafirmarse en el ejercicio de ese poder sobre un territorio, y ese territorio es el cuerpo de las mujeres y sus vidas.

\section{Conclusión}

A lo largo del trabajo puede confirmarse que es posible una relación positiva entre los análisis foucaultianos del poder, la subjetividad y la biopolítica y el feminismo, tomando una noción como nexo: la sexualidad y las formas en las que el biopoder se ejerce, no como exterioridad sino como una producción propia del biopoder. Y esta relación, gracias al aporte feminista, se da en el marco del patriarcapitalismo, que incluye prácticas políticas y ecónomicas y que repercuten en diferentes ámbitos de la vida.

El control del cuerpo y de la vida es históricamente acentuado sobre los cuerpos entendidos como femeninos, que son las cuerpas. $\mathrm{Y}$ esto es posible entenderlo desde la configuración de una moralidad masculina, que establece verdades universales, que moraliza y que se posiciona jerárquicamente sobre otro espacio, un territorio de resistencia que es el lugar de la mujer y lo femenino, asociado a lo íntimo, lo doméstico, lo subjetivo y apolítico.

La jerarquización de estos espacios es inherente a la estructura patriarcapitalista que dispone de estos espacios desde una lógica binaria, asumida desde una supuesta realidad prediscursiva, que es también una invención patriarcal. Esta realidad prediscursiva es del ámbito de la sexualidad y del género.

Los conceptos que se toman desde el feminismo de Michel Foucault, permiten analizar las prácticas sobre el cuerpo, de la misma forma que definen la noción de 
patriarcapitalismo. La relación más importante que surge de este encuentro es la de la biopolítica y las construcciones de la subjetividad en el patriarcapitalismo, en el juego biopoder-resistencia, donde se desprenden las relaciones éticas y las posibles respuestas de resistencia y ruptura, no solo éticas sino también estéticas.

El binarismo de género es la estrategia principal en el patriarcapitalismo y desde el cual se posibilita la emergencia del biopoder y sus aplicaciones. El varón moralizador y a la mujer sospechosa se disponen como dos lugares matrices del binarismo de género en la creación del valor moral. Los ámbitos donde se expresan los conceptos del varón moralizador y la mujer sospechosa son el sexo, el aborto, el parto y el femicidio, como lugares representativos de expresión del biopoder.

El concepto de sexualidad estructura las relaciones, y a través de él se observa el carácter ético y la posibilidad estética. La resistencia se da en este sentido: desde los aphrodisias que teorizó Foucault, como centro de placer, y la destrucción de la masculinidad como inversión de la moralidad patriarcal, desde el lugar femenino de la subjetividad. La autoconstitución del sujeto desde el placer es una aspiración ya puesta en Foucault, cuando plantea "hacer de la vida un arte", y también una propuesta que tiene un correlato en las luchas feministas por instaurar el control de sí mismas. La consigna "muerte al macho" tiene una significación en este sentido.

Conciliar la propuesta foucaultiana con el feminismo genera aportes en dos sentidos: por lado, la problematización del filósofo francés ofrece diversas herramientas para analizar la realidad biopolítica. Contar con un marco de análisis de estas características permite profundizar en los planteos referidos a lo que opera en el cuerpo y las estrategias con las que se arraiga, se produce y se ejerce, a la vez que abre la posibilidad de evidenciar la resistencia a ese biopoder en el despliegue de otras estrategias. Por otro lado, en las obras de Foucault, y en la historia de la filosofía en general, hay una gran ausencia de la posición de la mujer y lo femenino. Mostrar la desigualdad y el lado de la resistencia, rompiendo con la lógica binaria del patriarcado renueva la propuesta filosófica hacia otro lugar. No es menor recurrir a pensadoras mujeres para abordar una problemática biopolítica, al mismo tiempo que señalar de androcentrista a un filósofo reconocido. Eso es ya una propuesta revolucionaria. 


\section{Bibliografía}

Boyer, A. (2012) Biopolítica y filosofía feminista. Revista de Estudios Sociales, 43(pp. 131-138. Doi: 10.74400/res43.2012.11

Foucault, M. (1999) Estrategias de poder. Obras esenciales, vol. II. Barcelona, España: Ed. Paidós.

Foucault, M. (2001) Defender la sociedad. Buenos Aires, Argentina: Fondo de Cultura Económica.

Foucault, M. (2007) Historia de la sexualidad vol. I. Ciudad de México, México: Siglo XXI

Guattari, F. (16 de marzo de 2016) Para acabar con la masacre del cuerpo. Recuperado de: https://artilleriainmanente.noblogs.org/post/2016/04/16/felixguattari-paraacabar-con-la-masacre-del-cuerpo/

Nietzsche, F. (2003) Así habló Zaratustra. Madrid, España: Ed. Alianza.

Nietzsche, F. (2005) Más Allá del Bien y del Mal. Madrid, España: Ed. Alianza.

Posada, L. (2015). El "género", Foucault y algunas tensiones feministas. Estudios de Filosofía, 52 (2015): 29-43.

Revel, J. (2009) Diccionario Foucault. Buenos Aires, Argentina: Nueva visión.

Segato, R. (2010). Las estructuras elementales de la violencia: ensayos sobre género entre la antropología, el psicoanálisis y los derechos humanos. Buenos Aires, Argentina: Ed. Prometeo Libros.

Segato, R. (2016) La guerra contra las mujeres. Madrid, España: Traficantes de Sueños. 